\title{
An Intelligent Dispatch System Operating in a Partially Closed Environment
}

\author{
Augustus E. Ibhaze ${ }^{1}$, Ignatius K. Okakwu ${ }^{2}$, Ayobami T. Akinrelere ${ }^{3}$ \& Agbotiname L. Imoize ${ }^{1}$ \\ ${ }^{1}$ Department of Electrical and Electronics Engineering, University of Lagos, Lagos, Nigeria \\ ${ }^{2}$ Department of Electrical and Electronics Engineering, University of Benin, Benin City, Nigeria \\ ${ }^{3}$ Department of Electrical and Information Engineering, Covenant University, Ota, Nigeria \\ Correspondence: Agbotiname L. Imoize, Department of Electrical and Electronics Engineering, University of \\ Lagos, Lagos, Nigeria. E-mail: aimoize@unilag.edu.ng
}

Received: April 25, 2019 Accepted: June 8, 2019 Online Published: June 12, 2019

doi:10.5539/nct.v4n1p26 URL: https://doi.org/10.5539/nct.v4n1p26

\begin{abstract}
Taxicabs are very important in our daily lives and are reputed to be one of the mostly used forms of transportation. The cab dispatch system was first created to help passengers get through to taxi drivers and make it easier to book reservations. The evolution of cab dispatch system has moved from the ordinary callboxes to computer-aided dispatch system. These solutions were created to help organizations that own fleet of taxis manage and control their operations. Campuses and other partially closed environments also require these solutions but due to their high cost of implementation, they find it quite difficult to deploy and execute. In this paper, a smart dispatch system (SDS) is proposed. The system comprises of software and hardware units. The database and the android application make up the software unit while the microcontroller, the GSM module, and an android device constitute the hardware unit. The microcontroller intelligently reads and makes decisions based on the information received from the android device. The microcontroller also retrieves drivers' details from a database where all the information about the vehicles and drivers are stored. The GSM module acts as the intermediary between the android device and the microcontroller, and enhances the communication between the microcontroller and other devices. The system makes use of a microcontroller that selects a driver and dispatches it based on the capacity of the vehicle corresponding to the number of passengers in need. Consequently, an android application is built to be used by the clients making the request process much easier. The proposed system reduces human operator intervention, gives the passengers the estimated time for the dispatched cab to arrive at their bus stops thereby satisfying the clients in terms of cost efficiency and improved quality of service.
\end{abstract}

Keywords: callbox, microcontroller, smart dispatch system, taxicab, transportation

\section{Introduction}

Taxicab is a popular and most used form of transportation across the world. Driving a personal vehicle can be tedious due to heavy traffic in built up areas and in situations where one is too tired and indisposed; a taxi is very much useful and convenient. Owning and maintaining a car may be too expensive for many people and some environments do not even encourage the use of personal cars. As a result, there is an increasing number of operating taxicabs, and to organize their operations, a dispatch system is required to monitor and control the activities of taxi fleets. In the earliest system, taxi drivers communicated with operators using a callbox, a special telephone at a taxi stand, to communicate with the dispatch office. In recent times, intelligent transportation system has attracted many concerns in both academia and industry as suitable and efficient techniques for smart transportation systems keep evolving.

Vehicle dispatching is a process of assigning vehicles to customers or clients based on requests or orders being placed. Examples of industries that make use of the dispatch operation include courier, taxicabs, waste trucks or pickups, ambulance and the police (Stadium, 2013). The taxi dispatch operation began in the early 1970s, when taxi service demands increased. The demand-responsive transit (DRT) operations was created to offer services such as; dial-a-ride transportation services, shared-ride taxis and also provide special services to disabled individuals and senior citizens, a service better known as Americans with Disabilities Act of 1990 (ADA) public para-transit services (Kessler, 2004). 
Before the introduction of two-way radio dispatch system, taxi callboxes were used. They were located at taxi stands, where cabs would queue up and wait to render services. The callboxes were also situated at different strategic positions on the highways and drivers could use them to contact the control centre they were connected to in case of emergencies. The callbox is usually a metallic box that holds special purpose direct line telephone (Kouwen et al., 2018). The callboxes are usually connected to the control centre for the taxi companies where an operator is. The callboxes were used to contact the cab drivers and inform them of requests from customers by the dispatcher (Stone, Gilbert, \& Nalevanko, 1992).

Later on, more callboxes were deployed in various stops and customers could use them to call the nearest callbox located at a taxi stand and directly request for a locally situated cab. The taxi at the top of the queue would answer and get the time and address and accept provided the customer is nearby. The callboxes were also applied in police agencies, deployed on the street, and served as a way for police officers to report to their dispatch office. Callboxes offered the advantage of known locations in case of emergencies since they were installed in specific locations.

As new technology emerged, callboxes usage decreased as taxi drivers could not contact the control centre until one is spotted. In California, for instance the callbox usage has declined since 2001 by $80 \%$ as at 2010 (Cabanatuan, 2011). Another reason for decrease in usage was cost of maintenance. It was reported that in the state of Florida, it cost the state $\$ 1$ million per year to keep the boxes running even after a $65 \%$ decrease usage, hence the total decommissioning in 2014 (Morelli, 2013). Callboxes are still in use in campuses so students and staff can contact securities or authorities in case of emergency.

With the introduction of radio communication technology, taxis employed its use in dispatch operations. The operator communicates with the drivers via radio communicating devices installed in each vehicle. This system ensures continuous communication between the drivers and the operators. At the start, the operator or dispatcher calls the first on the shift or the next driver as the case may be and sends him the address of the client whose service is needed.

In a bid to improve dispatch accuracy, speed and utilization, the computer aided dispatch system was created. Also known as Computer-Assisted Dispatch (CAD) system, the system made use of computers to assist in recording information and receiving orders. The CAD system offers an easier tool to the dispatcher to handle orders effectively. The dispatcher with the computer aid is able to easily and quickly view status of all taxis and all orders received. Most recent CAD systems offer a wide range of services in a dispatch centre. Services provided by the CAD system now include call input, call resolution and disposition; call dispatching, call status maintenance, field unit status and tracking and many more options.

The introduction of a Mobile Data Terminal (MDT) further helped in making dispatching operations easier. The MDT or mobile digital computer (MDC) is a portable computer device that is fixed and installed into vehicle, such as the taxicabs and police cars, to make communication with the dispatch centre far easier. In addition, they are used to display information to the drivers such as client's details, directions, general news and other relevant information (Stadium, 2013).

The CAD system coupled with the MDTs offered three (3) basic benefits. These benefits encouraged many other countries to adapt the technology, as they were economical and more efficient (Voon \& Yow, 2010). Firstly, it helps dispatcher improve their current services. Improving dispatching and scheduling brings about efficiency. A greater efficiency brings about quicker response time and more vehicle utilization. Secondly, it offers higher quality services. This is arguably the most important benefits. Better scheduling and dispatching of taxis makes the service more reliable. Thirdly, it makes for better communication between passenger and dispatcher. It facilitates a better relationship between the operator and passenger. The process of requesting for a taxi has been made easier.

Another system called the GPS-based dispatch system integrates the Global Positioning System (GPS) into the already developed computer-aided dispatch system. With the GPS, monitoring becomes far easier and scheduling more accurate. Many research works have been carried out to predict how the application of a GPS system will be of advantage in terms of service and economically. The system is currently being implemented in Singapore and it is known as Automatic Vehicle Location and Dispatch System (AVLDS) (Voon \& Yow, 2010).

The AVLDS is a satellite-based dispatch system that implements differential GPS, computerized dispatch systems, interactive voice responses and wireless data communication (Liao, 2003; 2001). Just like the computer-aided dispatch system with mobile data terminals, the vehicles in this system are equipped with devices that transmit the location of the vehicle back to the dispatch centre and make it easier for the operator to decide who to dispatch based on the location of other vehicles.

For each taxi request, the system based on the location of the customer, searches for the nearest taxi to the customer 
by collecting the location details of the taxi provided by the GPS system using latitude and longitude. Taxicabs within a certain range of the customers receive the details of the orders via wireless transmission. The taxi driver receives and then accepts the order using the mobile data terminal device installed in his vehicle and the dispatcher sends the information of the taxi such as taxi number and estimated time using real-time and route to the customer (Voon \& Yow, 2010). The major benefits the GPS based dispatch system offers is improving the quality of service by dispatching taxis to customers based on the shortest distance. This benefits both the drivers and the customers. It will take less time for the customer to get a cab and for the driver to reach the customers via the shortest real-paths, which is the primary goal of a dispatch system (Seow, Dang, \& Lee, 2009).

\section{Related Work}

Arafat et al. (2017) proposed an integrated system of communication between a database, sensor nodes and a wireless cellular network as an intelligent transportation solution. David et al. (2017), proposed an assistive technology solution using radio frequency identification and Bluetooth technology to mitigate localization problems in transportation system. An alternative technique in implementing smart transportation system proposed by Benjamin and James (2017) implied the implementation of vehicle to infrastructure ideology in view of achieving an ecosystem of Internet of Things based transportation initiative. Following directly from the advances made in transportation system, communication between taxi owners and dispatch operator became easier using a 2-way radio and later on computer terminal (Computer-aided dispatch) (Salanova et al., 2011).

The computer-aided dispatch system makes use of mobile data terminals, which is a computerized device, planted in taxi making communication easier. This device also supports Global Positioning System (GPS), which relays the current location of each taxicab to the central office. According to Akira et al. (1997), the key to having a more effective dispatch system is having an accurate taxi location, good interpretation and accurate transmission of dispatch information to the drivers and shortest time to reduce delay. This research undertaking is aimed at improving taxi and shuttle services of a closed environment by employing a more suitable taxicab dispatch. The system will make use of an application on mobile devices to request a cab dispatch to a given location.

The problem of waiting tirelessly for a taxi, uncertain whether one is coming your way or going to your destination instead of getting an alternate means is eliminated. The taxi drivers also profit from this system as they get to conserve resources by going to areas where their services are needed (Woodhull, 1983). The challenge posed by the use of earliest techniques like callboxes marked by dispatch delays, human interventions and inefficient delivery has led to the development of computer-aided dispatch system. While the computer-aided dispatch system improved on dispatch delays, the need for human operators still pose some level of inefficiency This project is therefore geared towards eliminating the need for human operator with the motive of improving taxi cab dispatch systems' general performance. The long waiting queues marked by unavailability of taxi cabs as at when needed in high demand areas remain challenging as the demand for fast and efficient mobility services remains a large concern.

In environments, such as Nigeria, where a taxi is supposed to take more than one passenger for a roundtrip this system ensures taxi drivers know what area he is most likely to get sufficient customers. On many occasions, too many taxicabs crowd a particular bus stop with few customers while at another bus stop, many customers needing transport service are waiting tirelessly running late for whatever appointment they have made. In many countries, companies own taxis and there is an essential need for these companies to have full control of their taxis. Monitoring and organizing of the fleet of taxicabs is a very vital part of a transportation service. There is also the need for these companies to improve on their services to beat other competitors as proposed in the quality of service assessment based on customer satisfaction in (Monzon, Hernandez, \& Cascajo, 2013).

Woodhull (1983), in his study, divided into two the causes of unreliable services by transport workers. In his research, he categorized these causes into internal and external factors, what he termed endogenous and exogenous factors. Exogenous factors include traffic congestion and incidents, interferences due to wrong parking of other vehicles and on-going constructions and traffic signalization. Endogenous factors include driver's attitude and behaviour, inaccurate and improper scheduling and planning, route configuration, variable passenger demand (Woodhull, 1983).

For improved quality of service and control of the activities of the cabs, the dispatch operation was created and proved an ideal solution. The dispatch system includes an operating centre in which the function within a transit environment is to serve as the control centre of operations to ensure the availability of consistent transit service on the street each day (Christopher \& William, 2012). Many now provide door-to-door services and even special services for the elderly and disabled people (Häll, Andersson, Lundgren, \& Värbrand, 2009). The service involves customers sending their request for a cab to be sent to their location. 
Taxis are matched to customers according to the order in which the customers called and in recent times according to proximity (Stadium, 2013; Gan, An, \& Miao, 2014). One of the methods suggested by (Abkowitz, Slavin, Waksman, Englisher, \& Wilson, 1978) to improving transit service reliability is the operational method. It was suggested that the operational method, which included implementation of schedule modification and route restructuring, could help improve services rendered by the transport workers (Abkowitz et al., 1978). Irina et al. (2012) proposed that the reliability of public transport is a key factor in developing sustainable transport system and further investigated route reliability in terms of travel time and delay time. The dispatch system enables the transport companies to monitor their vehicles and drivers, make proper schedules and great control of the activities of the cabs.

\subsection{Car Dispatch System}

There are two basic processes involved in the dispatch operation shown in Figure 1; request process and dispatch process.

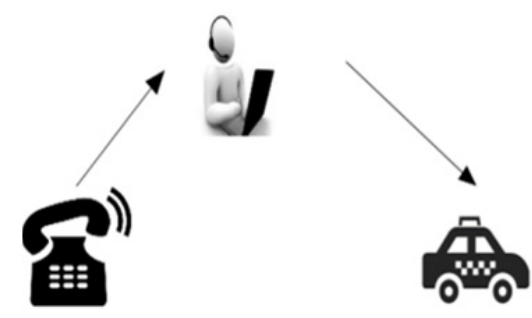

Figure 1. Cab dispatch flow diagram

\subsection{Request Process}

Customers' enquiry details are name of client, time and address of destination. These describe the various ways customers could make request for a taxi. Request can be made through short message service (SMS), telephone call, online website and recently, mobile application. While the short message service and telephone call have been in place for a long time, the mobile dispatch application is becoming very popular. The mobile application is quickly being integrated since many users can relate with apps for fulfilling many needs. Another reason the mobile application is being preferred is that customers do not have to go through the stress of being placed on hold by the dispatch operator and trying to communicate the right words since the mobile apps have options with names of possible locations. Therefore, the mobile dispatch application will be the major consideration for this project.

\subsection{Dispatch Process}

The dispatch process takes place in the operation centre. The dispatch operator receives the request via SMS, call or online and records the details. Depending on the system used in the dispatch operation centre, transfers the request to the taxi drivers. Some important equipment found in a dispatch operation centre include telephone receiving terminals, a network hub, customer management server, management data and communication server (Akira, Masaki, Koichi, \& Katsutoshi, 1997).

The customer management server organizes and records customers' information. The centre equipment is setup in a client-server configuration. This makes the equipment scalable. Once the operator receives the request for a service, he informs available drivers of the request and depending on the order adopted allocates a driver to the job. The taxi drivers can get the job by bidding, based on a first come first serve queue or based on the location of the service.

\subsection{Mobile Dispatch Application}

The smartphone is fast becoming the interface for anything that requires remote control, and the centre of online presence such as social networks and emails (Ericsson, 2014). Software design for mobile device will continue to increase for many years to come. Many now implement mobile application control into everyday life. An example is the home automation technology (Lafta, 2014; Hasan et al., 2015). Modern dispatch systems can now be designed completely using software and using mobile devices as in-vehicle unit or hardware, which is what the proposed system intends to achieve.

Some examples of taxi services in Europe that have integrated the mobile dispatch application include T-Dispatch, 
SAP SCM, DDS, Hailo, Taxi Magic, MTData and Uber. Uber is now being used in some parts of Nigeria such as Lagos and Abuja. Cosmina Ivan and Razvan Popa researched on the above mobile application in Europe and their functionality. They studied their advantages over the traditional call method and said since the dispatch system can be hosted in a public cloud and can therefore offer built in reliability and scalability. The mobile application also allows for payment online. For a request to be placed, the customer contacts the operation centre through any of the means mentioned above and puts in the request stating the present location, destination and agreeing on a fee.

\subsection{Benefits of Existing Cab Dispatch System}

The dispatch systems discussed above offer many benefits to both the customers and the taxicab companies. The parties involved, which comprises of the customer, the taxi driver and the dispatch operator all have less to do in terms of workload. This system is cost effective as the cab dispatch system helps to save cost in terms of fuel consumption. The unnecessary cruising of cab about a block or area is reduced. It minimizes delay since the system reduces the waiting time of customers. Customers can now make reservations in advanced thereby saving time. Also with a reliable service, customers can be sure of getting their allocated taxi.

Person-hour in terms of labour is drastically reduced since the computer assists in taking records of orders and of available taxis. The drivers especially profit a lot from this since they have to worry less. In addition, the dispatcher, with the introduction of the computer aids works more efficiently and accurately in managing the fleet of taxis. It fosters drivers' security since system offers a payment platform online, taxi drivers do not have to go about holding large sum of cash and this can prevent theft. Finally, the system assists companies with making organization and control of their fleet possible. The companies who own the fleet of taxis can control the activities of all vehicles and monitor the movement.

\subsection{Drawbacks of Existing Dispatch System}

One of the major drawbacks is customers' inability to get through the line. Booking a taxi via telephone is the most conventional means. Using a telephone to book, a cab has been the major means since the creation of the callbox (Voon \& Yow, 2010). However, while the telephone may be the most used and acceptable form, there may be times when the call to an operator might not go through. In times when demand for taxis is high, such as during a heavy rainfall or during rush hour, there might be so much traffic on the phone lines and some customers may not get through to make their requests.

Another limitation is the high cost of implementation. Implementing many of the systems discussed can be quite expensive. Installing the mobile data terminals into all the vehicles and setting up so many monitoring units in the dispatch centre will be of high cost. Maintenance of all these equipment will also be high and in situations where there are damages, they might have to be replaced. High operational cost of call centres is also a limitation. Many dispatch centres are open 24 hours a day and 7 days a week nonstop and even during the holidays which is one of the busiest time of a year. To maintain high quality service and a good working environment, the staffing cost will be high. Finally, communication barrier is another drawback, which could affect the performance of a dispatch service. There are situations where the customer is not able to communicate his needs properly to the dispatch operator during a call due to language barrier such as improper pronunciation of words or street names or accent obstacles.

\section{System Architecture}

The proposed system will follow the use case design for ordering taxi shown in Figure 2. The customer logs in on his android device. The android application is user friendly, and has predetermined options. Once logged in, the customer then selects his present location and has the option of selecting how many customers are waiting alongside him. The customer then submits the request, and gets informed of the message being sent. The information is transmitted to the microcontroller, which then transmits the request to an available driver in form of an SMS (Häll et al., 2009). 


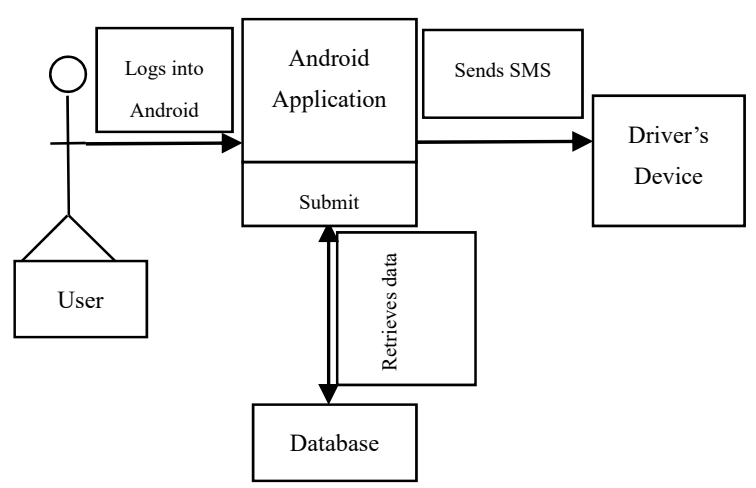

Figure 2. Use Case Design

The android application has the option for either the driver or a passenger to login. The drivers' information are stored on a database and retrieved by the microcontroller via the GSM module. The vehicles used are categorized into types based on their capacity. For instance, a Type 1 vehicle has a capacity of 5-6 people and a type 2 has a capacity of 18-28 passengers, and so when clients send a request for cab, they have the option of selecting the number of passengers they have with them and depending on the number, say 4 or 5 , an available type 1 vehicle is dispatched to them (Stadium, 2013).

\subsection{Design of Proposed Smart Dispatch System}

Fig. 3 shows the block diagram of the system design and describes the architecture of the system that brings about the functionality of the design. The various components involved in the system and their connections are explained. In addition, the individual role of each component and the total functionality as a whole to make it a system are discussed. The system, as mentioned earlier, can be classified into two considerations; the hardware and the software. The hardware constitutes the physical equipment used in the system and their connections while the software deals with the program instructions working behind the system.

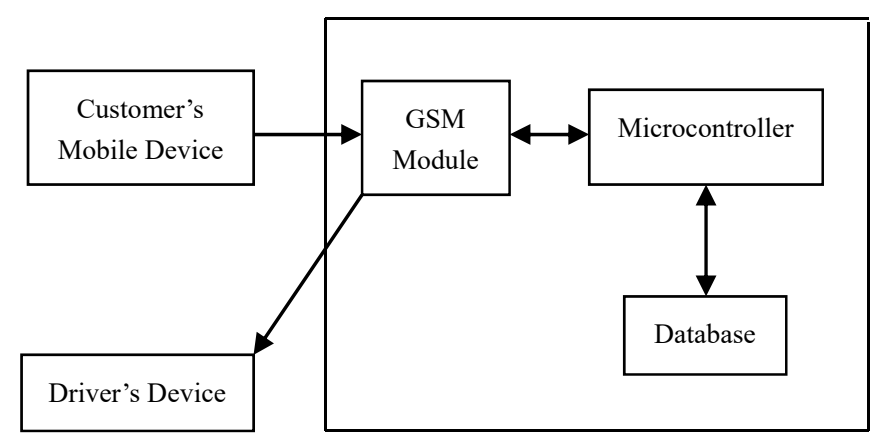

Figure 3. System Block Diagram

\subsection{Hardware Unit}

The hardware design consists of the microcontroller, the GSM module and an android phone or tablet. The android phone will be used to send information and requests to the microcontroller. The android application will be installed on the phone or tablet and information can then be inputted and transmitted to the controller.

The microcontroller is at the heart of the whole project. It intelligently reads and makes decisions based on the information received from the android device. The microcontroller also retrieves drivers' details from a database where all the information about the vehicles and drivers are stored. The GSM module helps the communication between the microcontroller and other devices. It is the intermediary between the android device and the microcontroller.

\subsection{Microcontroller Unit}

The microcontroller is more or less a little computer. They are specially designed computer that carry out 
instructions (Kessler, 2004). They are embedded inside devices to control the actions of the device and for this reason, they are also called embedded controller. The microcontroller is a single chip device that contains processor along with memory and interface devices on the same integrated circuit chip and uses internal bus to communicate with other devices. The processor operates like the Central Processing Unit (CPU) of a computer that executes program instructions (Abkowitz et al., 1978). The microcontroller is at the centre of the system and executes instructions that are fed into it. It intelligently searches for an available driver and sends an SMS to the selected one. The microcontroller searches the database for a driver with the type of car needed based on capacity and if available and informs him of a request made.

For the purpose of this design, Arduino Uno is used. The characteristics of the Arduino Uno microcontroller include; 14 digital input/output pins and of the 14,6 are used as PWM (Pulse Width Modulation) outputs, 6 analog inputs, a USB connection, a power jack and a reset button. The Arduino Uno operates on $5 \mathrm{~V}$ and permits an input voltage of $6-20 \mathrm{~V}$. It has a clock speed of $16 \mathrm{MHz}$ and a flash memory of $32 \mathrm{kB}$ of which $0.5 \mathrm{kB}$ is used by boot loader.

The bootloader enables users to upload the required programs to make microcontroller work. It can be powered either by a USB connection or with an external power supply. The external supply can be a battery or an adapter. A battery will be used as the source of power for this project since the needed supply is between $7-12 \mathrm{~V}$ as recommended by the manufacturers. Supplying beyond a $12 \mathrm{~V}$ could damage the controller board. The 14 digital pins can be used as either an input or output depending on the program

\subsection{GSM Module}

The GSM module works just like the regular modem. It can be integrated with equipment. It is similar to the GSM mobile phones and just like a mobile phone, requires a SIM card to operate. The GSM module is in control of the communication between the microcontroller and the mobile devices. The GSM module sends and receives information. It is used to aid the retrieving of available drivers' information from the database. The module will also be used to send text messages to the driver's device when a request is made.

The preferred GSM module for the sake of this project is the SIM 800L. The SIM 800L is preferred due to its availability and cheap cost. The SIM $800 \mathrm{~L}$ operates on voltage range of $3.4-4.4 \mathrm{~V}$ with a recommended voltage of 4V. The GSM module will be physically connected to the microcontroller and receives instructions while communicating with it. The microcontroller will power the module but connecting the SIM 800L directly to the controller could damage it because the output voltage of the controller is $5 \mathrm{~V}$ and required voltage is $4 \mathrm{~V}$. The microcontroller controls the GSM module by sending AT commands via its serial interface.

\subsection{Software Unit and Database Design}

The database and the android application make up the software unit. The user to request for a taxi service uses the android application. The database stores up drivers' information with their corresponding vehicle details such as the capacity. When a request is sent, a driver's number is retrieved from the database so that an SMS can be sent.

The database is a collection of organized information for easy accessibility and management. A relational database, which stores information in form of a table, is used for the system. Relational databases are created using MySQL (structured Query Language). MySQL is very suitable due to its flexibility and speed. It uses a structured language to create, read, update and delete a database. The database makes use of a platform known as XAMPP, which is open source cross web server solution stack package. XAMPP is an acronym for all operating system Apache, MySQL, PHP and PERL. In addition, a simple site is created to communicate with the database using PHP (Hypertext Pre-processor). The main use of the site is to respond to changes in the status of the availability of the drivers. The site is made dynamic and responsive with the use of PHP.

A simple android application will be needed to send requests by the clients and be accessible by the taxi drivers. The Android application can be easily created using an application that makes it possible to create one using already created templates without necessarily having any coding skill.

\section{System Implementation}

\subsection{Basic Requirements}

The following are the requirements needed for this system to function effectively. System users are able to use this system effectively when the requirements are met. The software requirements to be met for this system to run effectively include Internet access and a SIM card with sufficient airtime for SMS.

The major hardware equipment needed to ensure the functionality of this system is the microcontroller implementation shown in Fig. 4 and the android device. 


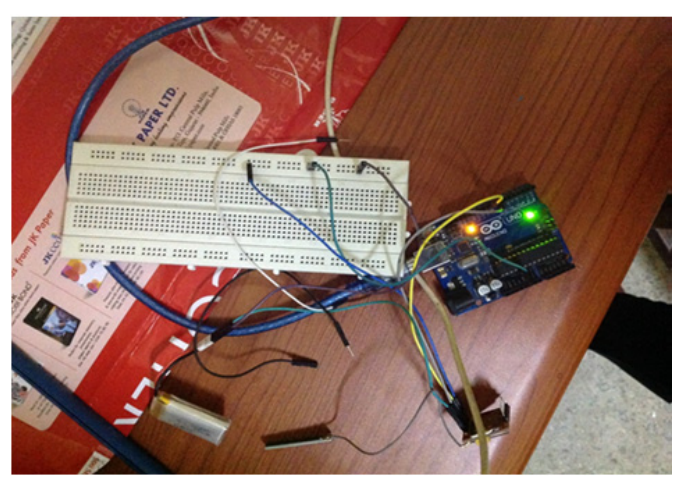

Figure 4. Hardware System Setup

\subsection{Android Program}

The programs written in the Arduino IDE is compiled, tested, and checked for errors. The program, written in C language, is then uploaded into the Arduino board using the IDE tool. The program is also used to send instructions into the GSM module via the controller. The GSM module as mentioned in the previous session makes use of AT command. To test for availability and signal quality when a SIM card is inserted into the module, the AT command used is as follows. The command is used to check for signal quality and confirm connectivity of the GSM module.

If SIM 900 available()!=0

SIM900.printIn(AT+CSQ)

\subsection{Software Implementation}

After successful installation of the android application and registration, the application makes it possible to send a request in a predetermined format. When a user opens the application, the home page displays an option to login as a user or a driver.

The driver's interface has the option to select when he is available, which when selected automatically changes the status in the database. Selecting the 'I'm Free' and connects to an HTTP link which resets the status from busy, indicated in the database as ' 0 ' to available, indicated by ' 1 '. When the driver receives a request, the status is automatically reverted to ' 0 ' (busy). The customer's interface provides the possibility of making request based on location within the closed environment.

\subsection{Cost Benefits of the Proposed Design}

Table 1 shows the cost implication of various techniques used such as the call box technique (Nee, Carson, \& Legg, 1996), Computer-Aided Dispatch (CAD) system and the Smart Dispatch System (SDS) proposed in this study. The cost comparison is done using the Nigerian local currency in Naira. The proposed SDS is seen to be cheaper than the previously deployed technologies.

Table 1. Table of Comparison between Callbox, CAD and SDS

\begin{tabular}{|c|c|c|c|}
\hline $\mathbf{S} / \mathbf{N}$ & Dispatch Technology & $\begin{array}{l}\text { Implementation cost (Naira per } \\
\text { unit) }\end{array}$ & Percentage Ratio (\%) \\
\hline 1 & Callbox & $1,050,000$ & 25.8 \\
\hline 2 & Computer-aided dispatch (CAD) system & $3,000,000$ & 73.7 \\
\hline \multirow[t]{2}{*}{3} & Smart Dispatch System (SDS) & $20,501.25$ & 0.5 \\
\hline & TOTAL & $4,070,501.2$ & 100 \\
\hline
\end{tabular}

\section{Conclusion}

The dispatch system was created to solve the delay problem passengers often go through at the bus stops. Past systems which proved useful to solve the initial problem in neglected areas such as campuses that have difficulty in implementing such expensive solutions. The proposed smart dispatch system (SDS) therefore achieves the main 
purpose of improving the quality of service of taxis while reducing the cost of implementation and human operator intervention. The android device enables real-time calculation of distance between the customer and the dispatched taxicab. This system, which calculates the distance, and the time it will take to arrive at different bus stops, will give the passengers the estimated time for the dispatched cab to arrive at their bus stops thereby satisfying the client. Future work would focus on improving the efficiency of the smart dispatched system for enhanced user experience.

\section{Acknowledgment}

The authors thank the University of Lagos and Covenant University for support.

\section{References}

Abkowitz, M., Slavin, H., Waksman, R., Englisher, L. S., \& Wilson, N. H. (1978). Transit service reliability (No. DOT-TSC-UMTA-78-18). United States. Urban Mass Transportation Administration.

Akira, I., Masaki, T., Koichi, H., \& Katsutoshi, O. (1997). Automatic Dispatching System with GPS. Fujitsu Ten Technical Journal, 10, 23-34.

Al-Dweik, A., Muresan, R., Mayhew, M., \& Lieberman, M. (2017, April). IoT-based multifunctional scalable real-time enhanced roadside unit for intelligent transportation systems. In 2017 IEEE 30th Canadian conference on electrical and computer engineering (CCECE) (pp. 1-6). IEEE.

Cabanatuan, M. (2011). Highway call boxes becoming obsolete. SFGATE (Hearst Communications, Inc.), San Francisco. 2011.

Christopher, D., \& William, M. (2012). Best Practices in Bus Dispatch. National Centre for Transit Research, University of South Florida, Florida.

Ericsson. (2014). Ericsson Mobility Report. Ericsson, Sweden.

Fernandez-Llorca, D., Minguez, R. Q., Alonso, I. P., Lopez, C. F., Daza, I. G., Sotelo, M. A., \& Cordero, C. A. (2017). Assistive intelligent transportation systems: The need for user localization and anonymous disability identification. IEEE Intelligent Transportation Systems Magazine, 9(2), 25-40. https://doi.org/10.1109/MITS.2017.2666579

Gan, J., An, B., \& Miao, C. (2014, May). An efficient algorithm for taxi system optimization. In Proceedings of the 2014 international conference on Autonomous agents and multi-agent systems (pp. 1465-1466). International Foundation for Autonomous Agents and Multiagent Systems.

Häll, C. H., Andersson, H., Lundgren, J. T., \& Värbrand, P. (2009). The integrated dial-a-ride problem. Public Transport, 1(1), 39-54. https://doi.org/10.1007/s12469-008-0006-1

Hasan, R., Khan, M. M., Ashek, A., \& Rumpa, I. J. (2015). Microcontroller Based Home Security System with GSM Technology. Open Journal of Safety Science and Technology, 5(02), 55. https://doi.org/10.4236/ojsst.2015.52007

Kessler, D. S. (2004). Computer-aided scheduling and dispatch in demand-responsive transit services (No. 57). Transportation Research Board.

Kouwen, A., Scanlon, M., Choo, K. K. R., \& Le-Khac, N. A. (2018). Digital forensic investigation of two-way radio communication equipment and services. Digital Investigation, 26, S77-S86. https://doi.org/10.1016/j.diin.2018.04.007

Lafta, H. A. R. (2014). Design and Implementation of Appliance Controller using Traditional or Smart Phone. International Journal of Computer Applications, 101(9). https://doi.org/10.5120/17718-8762

Liao, Z. (2001). Taxi dispatching via global positioning systems. IEEE Transactions on Engineering Management, 48(3), 342-347. https://doi.org/10.1109/17.946533

Liao, Z. (2003). Real-time taxi dispatching using global positioning systems. Association for Computing Machinery. Communications of the ACM, 46(5), 81-81. https://doi.org/10.1145/769800.769806

Monzon, A., Hernandez, S., \& Cascajo, R. (2013). Quality of bus services performance: benefits of real time passenger information systems. Transport and Telecommunication, 14(2), 155-166. https://doi.org/10.2478/ttj-2013-0013

Morelli, K. (2013). Florida dismantling call boxes along interstates. The Tampa Tribune, Florida.

Nee, J., Carson, J. L., \& Legg, B. (1996). An Evaluation of Motorist Aid Call Boxes in Washington (No. WA-RD 
420.1). Washington State Transportation Commission.

Rhoades, B. B., \& Conrad, J. M. (2017, March). A survey of alternate methods and implementations of an intelligent transportation system. In SoutheastCon $2017 \quad$ (pp. 1-8). IEEE. https://doi.org/10.1109/SECON.2017.7925303

Salanova, J. M., Estrada, M., Aifadopoulou, G., \& Mitsakis, E. (2011). A review of the modeling of taxi services. Procedia-Social and Behavioral Sciences, 20, 150-161. https://doi.org/10.1016/j.sbspro.2011.08.020

Seow, K. T., Dang, N. H., \& Lee, D. H. (2009). A collaborative multiagent taxi-dispatch system. IEEE Transactions on Automation science and engineering, 7(3), 607-616. https://doi.org/10.1109/TASE.2009.2028577

Stadium. (2013). Technical Manual on Transport from International Olympic Committee. Stadium ITS for large events, Brussels.

Stone, J. R., Gilbert, G., \& Nalevanko, A. (1992). Assessment of computer dispatch technology in the paratransit industry (No. DOT-T-92-23). United States. Joint Program Office for Intelligent Transportation Systems.

Voon, K. T., \& Yow, K. C. (2010, August). GSM positioning-based taxi booking and dispatch system. In proceedings of the 10th WSEAS International Conference on Applied Informatics and Communications, and 3rd International Conference Biomedical Electronics and Biomedical Informatics (pp. 25-30)

Woodhull, J. (1983). Issues in on-time performance of bus systems. Unpublished paper. Los Angeles, CA: Southern California Rapid Transit District.

Yatskiv, I., Pticina, I., \& Savrasovs, M. (2012). Urban public transport system's reliability estimation using microscopic simulation. Transport and Telecommunication, 13(3), 219-228. https://doi.org/10.2478/v10244-012-0018-4

\section{Copyrights}

Copyright for this article is retained by the author(s), with first publication rights granted to the journal.

This is an open-access article distributed under the terms and conditions of the Creative Commons Attribution license (http://creativecommons.org/licenses/by/4.0/). 